\title{
THE NATURE AND EFFECTIVENESS OF CORRECTIONAL TECHNIQUES
}

\author{
Donald R. Cressey*
}

I

\section{INTRODUCTION}

The criminological and penological literature contains two principal conceptions of "correctional techniques." The older conception considers as correctional techniques those general systems and general programs used for handling criminals and assumed to be somehow reformative. Thus, imposition of either physical or psychological pain, in any of a variety of settings, continues to be viewed as a general system for correcting criminals. Similarly, one rationale for introducing and maintaining general programs such as probation, parole, and imprisonment has been that these programs are or will be more "correctional" than the programs used in the past. A newer conception of "correctional techniques," however, places more emphasis on the specific methods used in attempts to change individual criminals. While descriptions of such methods are by no means as precise as descriptions of medical techniques, an analogy with clinical medicine is made, with the result that utilizing the methods is called "treatment" or "therapy." Thus, within a parole or probation organization, the agents may help offenders find jobs, order them to stay out of saloons, or counsel them on psychological problems of adjustment. Because each of these maneuvers is assumed to have some efficacy in changing criminals into noncriminals, each is viewed as a treatment or correctional technique. Similarly, prisoners may be enrolled in prison schools, ordered to work, given vocational counseling and training, or engaged in individual or group psychotherapeutic interviews. These specific programs also are viewed as techniques.

This paper will be devoted to closer identification of these two conceptions of correctional techniques, to discussion of the problems involved in measuring the effectiveness of "techniques" defined in either the first or the second sense, and to exploration of possible reasons for reluctance to define "correctional techniques" more precisely.

* B.S. 1943, Iowa State College; Ph.D. 1950, Indiana University. Chairman, Department of Anthropology and Sociology, University of California, Los Angeles; Research Consultant, California Department of Corrections; Research Advisory Board, California Board of Corrections. Sociologist, Illinois State Penitentiary, 1949; Research Associate, United States Penitentiary, Terre Haute, Indiana, I95I; Research Associate, California Institution for Men, 1950-5I; Research in the Wisconsin State Prison and the Wisconsin State Reformatory, 1955-56, while attached to the Center for Education and Research in Corrections, University of Chicago. Author, Otrier People's Money (1953); co-author [with Edwin H. Sutherland], Principles of Criminology (5th ed. 1955). Contributor to sociological, legal, and correctional publications. 


\section{General Systems and Programs}

During the past two centuries, the principal societal reaction to criminality in the United States has been punitive. Punishment for criminals is pain or suffering intentionally inflicted by the state because of some value the pain or suffering is assumed to have. In administration of the criminal law, we have assumed that one value stemming from infliction of pain on offenders is reformation or, in a newer terminology, "rehabilitation" or "correction" of those offenders. Other values, such as deterrence, are also assumed, but it is the idea that punishment reforms which makes the infliction of pain a correctional technique in the broadest sense of the term. Consistently, the general programs used for implementing the punitive reaction to crime also have been viewed as correctional techniques. Physical torture, social degradation, restriction of wealth, and restriction of freedom are among the programs used for inflicting pain on criminals. At present, the most popular techniques of this sort are restrictions on wealth (fines) and restrictions on liberty (imprisonment).

Strangely, in the criminological literature, practically no space is given to discussion of the reformative value which the imposition of fines is assumed to have. Of seven recent criminology textbooks, two discuss only casually the possible rehabilitative effect of fines, ${ }^{1}$ and five scarcely touch the topic at all. ${ }^{2}$ Diseussion of inflicting pain by imprisonment is a different matter. From the time of its invention, the prison has had its loud supporters and loud critics.

As a general program for dealing with criminals, the prison, like the mental hospital, performs an integrating function for society. ${ }^{3}$ This function, in turn, is assumed to have two principal aspects. First, the prison is expected to restore society to the state of equilibrium and harmony it was in before the crime was committed. "Undesirables," "deviants," "nonconformists," "outlaws," etc., are segregated behind walls. Second, the prison is expected to contribute to social integration by reducing the occurrence of future crimes. This latter aspect of the prison's integrative function is performed in two different ways. On the one hand, crime rates are assumed to be kept minimal both by the deterrent effects of imprisonment and by the effect that imprisoning men has on reinforcing the anticriminal values of the society doing the imprisoning. ${ }^{4}$ On the other hand, imprisonment is expected to reduce crime rates by changing criminals into noncriminals. It is the last goal of prisons which

\footnotetext{
${ }^{1}$ Robert G. Caldwell, Criminology 427 (1956); Walter C. Reckiess, The Crime Problem 559 (2d ed. 1955).

${ }^{2}$ Harry E. Barnes \& Negley K. Teeters, New Horizons in Criminology (2d ed. I95I); Ruth Shonle Cavan, Criminology (2d ed. 1955); Mabel A. Elliott, Crime yn Modern Society (1952); Edwin H. Sutherland \& Donald R. Cressey, Principles of Cruminology (5th ed. I955); Donald R. TAFt, Criminology (3d ed. x956).

${ }^{3}$ Parsons, Stggestions for a Sociological Approach to the Theory of Organization, II, I ADM. ScI. Q. $225(1956)$.

- See Emile Durkheim, The Division of Labor in Society 70-i io (Free Press ed. 1949).
} 
gives imprisonment, as a general program, the character of a "correctional technique."

It must be emphasized that support for continuing the punitive reaction to crime or for specifically implementing this reaction by imprisonment is always based on some value which punishment generally or the specific kind of punishment inflicted by the fact of incarceration is assumed to have. We do not have any objective, scientific evidence that inflicting pain on criminals is an efficient system for maintaining, or restoring, social integration. We do not know that imprisoning men deters others, reinforces anticriminal values, corrects criminals, or in some other way promotes social solidarity. Neither do we know that inflicting other kinds of pain corrects criminals or, generally, integrates society. Moreover, we do not know that inflicting pain by imprisonment or some other means is an inefficient system for achieving the desired ends.

In recent years, there has been a distinct trend away from the notion that inflicting pain reforms criminals. Also, it is now fashionable to argue that prisons do not correct and that, therefore, they should be abolished ${ }^{5}$ or so modified that they become hospitals rather than places of punishment. ${ }^{6}$ But neither the trend nor the fashionable arguments are based on scientific evidence that punishment is not effective as a general correctional technique. This is true simply because there never has been an acceptable measure of "efficiency." How much integration is necessary before a society is integrated? How low must a recidivism rate be before it can be said to be minimal? This kind of fairy-tale question can lead only to fairy-tale answers: "some," "enough," "lower that at present."

Currently, it is possible to argue, for example, that recidivism rates are high and that this has resulted because punishment is not inflicted with enough certainty or severity. It also is possible to argue that the rates are low (lower than they would be if . ... ) because we have been using some punishment, at least. Alternatively, it can be argued that the rates are high because punishment is being used, and that the rates are low because punishments have been becoming less severe. No study has ever demonstrated that one of these arguments is more cogent than the other.

Moreover, even if a fixed bench mark of some kind could be established and we could discern that the recidivism rate moved above or below it after some general program was introduced, we still could not attribute the increased "efficiency" or "inefficiency" to the change of program. For example, measuring the effectiveness of parole, as compared to the effectiveness of the earlier system of determinate sentences, is complicated by variations in use of probation and by variations in the nature of parole itself. Also, a finding that recidivism rates are higher or lower after the introduction of a parole program can easily be attributed to any of numerous conditions which might have occurred simultaneously with the introduction of the

\footnotetext{
s John Bartlow Martin, Break Down the Walls (1954).
}

'Karpman, Criminality, Insanity, and the Law, 39 J. Crim. L. \& CRIMInotogr 584 (1949). 
program. Among these are differential arresting, sentencing and prison practices, and differentials in the total populations from which criminals are selected.

The above comments refer only to some of the difficulties involved in measuring the effect of general programs on recidivism. When we attempt to evaluate the effects on the entire society, the difficulties are compounded. For example, there is no way of knowing whether crime rates are higher today, when punishments appear to be relatively mild, than they were some years ago, when punishments were more severe. Accordingly, we cannot know whether punishment does or does not deter criminals or reinforce anticriminal values. The numerous essays pointing out the inadequacies of statistics on crime agree on at least one point: We have no measure of the crime rate; we have only what are said to be "indices" of it." The "indices" we use, however, such as "crimes known to the police," are not indices at all, for the relationship between the set of statistics used as an "index" and the true crime rate cannot be determined. Since there is no way to determine how many crimes are committed, we can only guess that crime rates are increasing, decreasing, or remaining the same, and we can only guess that an "index" bears some constant relationship to what is happening to the true crime rate. This vagueness, in turn, makes it necessary for us to use only nonscientific or pseudoscientific data as bases for arguments to the effect that a general system, such as punishment, or a general program, such as imprisonment, is or is not effective. Thus, a statement that the prison is a failure because it has not efficiently performed its integrating function must be based on humanitarian, political, or other nonscientific grounds, for there can be no scientific data underlying the statement. Neither is there any scientific evidence that the prison has been a "success" in this regard.

\section{III}

\section{SPECIFIC METHODS}

By adopting the newer, more restricted conception of "correctional techniques," we do not necessarily avoid the methodological difficulties involved when general systems and programs are taken as the unit of observation. Statements regarding the effectiveness of specific procedures which are assumed to implement some general system for handling criminals, such as punishment, or which are part of some general program, such as imprisonment or parole, are subject to reservations which are identical to those placed on statements about the systems and programs themselves. This is evident from the fact that we can only assume that a specific technique such as "psychotherapy" or "strict discipline" is or is not corrective.

Currently, academicians and the members of professions involved in correctional work ordinarily assume that any real correctional technique is nonpunitive in nature. Only a generation ago, it was common to assume that a specific correctional tech-

'See, e.g., Grünhut, Statistics in Criminology, Ix4 J. Royal Statistrcal Ass'N 139 (1951); Sellin, The Significance of Records of Crime, 67 L. Q. Rev. 496 (1949); and Sellin, The Measurement of Crime in Geographic Areas, 97 Proc. AMr. Philos. Soc'y I63 (1953). 
nique was a method for implementing society's punitive reaction to crime, but the popular assumption at present is that a technique for inflicting punishment cannot be corrective. Because of this assumption, we are rapidly coming to substitute the word "treatment" or "therapy" for the word "correction" or "reformation." Saying that a method is a treatment or therapeutic technique is, then, simply a way of saying that the users of the technique do not make the traditional assumption that intentional infliction of pain is corrective. Psychotherapy, vocational education, counseling, and even direct financial assistance are viewed as "corrective" principally because they are nonpunitive, not because they have been demonstrated as effective methods for changing criminals into noncriminals. There is no scientific evidence that any nonpunitive correctional technique of this kind is either more or less effective than were punitive techniques such as "teaching discipline," "instilling fear of the law," and "breaking the will."

The paucity of scientific data on effectiveness or ineffectiveness of specific methods for dealing with individual criminals is not owing merely to oversight or lack of scientific interest in evaluation. On the contrary, many taxpayers have sincere interests in determining whether or not their money is well spent, and social scientists have keen interests in evaluating the effectiveness of techniques which are consistent, or even inconsistent, with some theory of crime causation they might hold. Explanation of our lack of clear conclusions about various techniques is difficult and complex. Perhaps we have few clearly-evaluative studies for the same reason that we have no crime statistics which are clearly valid: We cannot afford to let them appear.8

\section{IV}

\section{Dilemmas of Evaluative Research}

Precise research on the "success" of either general programs of crime control or more specific methods of correction furnishes information which is the basis for public esteem and professional reputation, as well as information about the correctional technique being evaluated. These two are very different. Personal and organizational needs supplement the societal needs being met by administration and utilization of various correctional techniques. For example, by utilizing or advocating use of particular techniques in correctional work, a person may secure employment and income, good professional reputation, prestige as an intellectual or scholarly authority, the power stemming from being the champion of a popular ideology, and many other personal rewards. An agency organized around administration of a technique may fill such needs for dozens, even hundreds, of employees, and may itself have more general, organizational needs for survival. Hence, evaluative research results which would show that the technique is ineffective and would, thereby, seriously threaten the agency or the personnel must be avoided if possible.

There are two principal ways to avoid the possibly unfavorable consequences of

${ }^{8}$ See Cressey, The State of Criminal Statistics, 3 N.P.P.A.J. 230 (1957). 
evaluative research. The first, and simplest, method is to insure that such research is not initiated either by the persons utilizing the technique or by outsiders. Few personnel administering correctional programs in prisons or in parole agencies, for example, have either the research training or the time necessary for evaluating the effectiveness of their work. Further, practical correctional workers are likely to screen carefully the sociologists, psychologists, and, most of all, newspaper reporters who want to poke around in their bailiwick. This is necessary. Unsympathetic researchers or reporters are almost certain to "misunderstand" some of the events and conditions they observe, and a "scandal" could wreck the chances of doing any correctional work. A currently more popular method for avoiding any unfavorable consequences of evaluative research, however, is to permit or even undertake the research, while insuring that any results will be subject to interpretation as "inconclusive."

In the past decade, we have in the United States witnessed tremendous growth of interest in research which would evaluate various action programs dealing with human relations-in mental hospitals, factories, governmental bureaus, correctional agencies, and other organizations-and it is now almost essential that one "be in favor of" evaluative research if he is to maintain a reputation as a good correctional worker or theoretician. This presents the personnel utilizing correctional techniques with a dilemma. On the one hand, one's reputation depends in part upon his being in favor of evaluative research. On the other hand, such research might threaten the very existence of an agency and damage the reputations of the personnel. Fortunately, there is a solution to the dilemma. Stated simply, it is to insure that any research results can be interpreted as "conclusive" if they favor continued utilization of the technique and as "inconclusive" if they do not. For example, it is important that we be able to attack a research study on methodological grounds, pointing out that it really did not measure the effects actually being produced by the technique in whose administration we have a personal stake. Ultimately, evaluative research furnishes grounds for public opinion and, in the case of public agencies, at least, grounds for legislative action. Accordingly, if we really "believe in" our techniques, we will, as good Americans and good public servants, "fight for them." One way to do this is to insure that any adverse administrative or budgetary decisions based upon the research can be countered by an exposé of a poor or incomplete research design. In a sense, we attack research methods in the behavioral sciences as being too imprecise, while at the same time maintaining research conditions which make precision impossible.

Even the behavioral scientists themselves are not immune. Because of personal investments, academic theoreticians (like the writer) are likely to argue that criminals are being corrected by any technique which is, or seems to be, consistent with a

'At least one school of thought maintains that public employees are not mere "servants" or agents of public purpose; they are, on the contrary, expected to have their own views of their mission and of appropriate policy. See Monypenny, The Control of Ethical Standards in the Public Service, 297 AnNaLs 98 (1955). 
favored theory of crime causation or of personality change. For the same reason, personnel of agencies devoted to rehabilitating criminals are likely to maintain that criminality is reduced by whatever it is that they are doing. Moreover, the implication is likely to be that crime is caused by whatever it is the agency is trying to correct. Administrators of a prison containing a school, a work program, individual psychotherapy, a recreational program, and strict discipline will almost inevitably maintain a "multiple-factor" notion regarding crime. They can scarcely do otherwise, for some external groups having strong interests in the prison maintain that crime is caused by educational "factors," others maintain that it is caused by economic "factors," others by personal or psychological "factors," still others by group "factors," and so on. The administrator must attempt to satisfy, or pacify, each of these groups. He is directed to believe that all the various techniques are necessary for the rehabilitation of a maximum number of inmates. He cannot risk abandoning any of them, for to do so might seriously threaten his budget and his personal prestige in the community. Consequently, it is highly desirable that any study designed to test the effectiveness of one of the techniques be subject to interpretation as "inconclusive," no matter how carefully or scientifically it is conducted.

For example, a research study which seemed to show that attending a prison school had little or no effect on the reformation of criminals would not necessarily lead to abandoning the school program. Rather, the "intangible benefits" of education probably would be enumerated, or, more likely, the study would be attacked on the ground that some variable, such as selection of the "least amenable" prisoners for education, was not controlled. In our society, education is a Good Thing, and schools must be maintained in prisons and justified as corrective ("good" men are educated; therefore, to make bad men good, educate them), whether or not there is any scientific evidence of their effectiveness.

Most of the difficulties arising in attempts to measure the effectiveness of correctional techniques stem, then, from failure to define precisely what a correctional technique is. This failure, in turn, seems to be a consequence of the fact that the groups controlling correctional agencies maintain widely divergent theories about crime causation and about what the agencies should do. Agency personnel cannot go "all out" to test one group's theory if doing so subjects them to severe criticism from that or another group. Since we do not know how to change criminals, we can only experiment with different techniques. Yet, as we have indicated, the fact that agencies are owned by persons with vested interests in their operation means that no experiment can be definitive.

This system for perpetuating criminological and penological ignorance has a highly useful function: It narrows the areas in which disagreement can occur. "Inconclusive" studies of the effect of correctional programs serve a useful purpose by harmonizing widely-divergent ideological and theoretical commitments held by the many persons who must deal with criminals. Personnel such as police, guards, social workers, judges, industrial foremen, teachers, clubwomen, district attorneys, min- 
isters, psychiatrists, and baseball coaches have very different notions about how to correct criminals, but these differences cannot result in embarrassing public denunciations or even serious private disagreements so long as no precise evidence favorable to one or the other group arises. Just as vague, common-sense, and "umbrella" terms are useful to interdisciplinary crime commissions and research teams because they reduce the area about which disagreement can be expressed (thus indicating high degrees of consensus when, in fact, no one knows what his colleagues are talking about), so vague definitions of "correctional techniques" and vague systems for evaluating the effectiveness of such techniques are useful because they decrease the range of points on which disagreements can occur. ${ }^{\mathbf{1 0}}$

\section{$\mathrm{V}$}

\section{A Vocabulary of Adjustment}

Personnel maintaining either theoretical or practical interests in the control of crime and delinquency have developed a rich vocabulary of motives for justifying as "corrective" whatever it is they are doing. Perhaps we developed the vocabulary during a period when concern for precise evaluation was not great and continue it in order to "show" that any research on the effectiveness of our favored technique or program is inconclusive. So that this vocabulary can be illustrated, let us assume that a state has passed a law requiring all its parole agents to be registered psychiatrists who will use professional psychiatric techniques for rehabilitating parolees. Let us assume further that the required number of psychiatrists is found and that after ten years, a research study indicates that introduction of psychiatric techniques has had no statistically significant effect on recidivism rates-the rates are essentially the same as they were ten years earlier. The following are ten kinds of overlapping themes which are likely to be popular among the personnel with personal interests in continuing the program.

I. "You can't use rates as a basis of comparison-if only one man was saved from a life of crime the money spent on the program is justified."

2. "Even the New York Yankees don't expect to win all their ball games; the program certainly contributed to the rehabilitation of some of the clients."

3. "Recidivism is not a good criterion of efficiency; 'clinical observation' indicates that the criminals handled psychiatrically are 'better adjusted' than were the criminals going out of the system ten years ago and that even the repeaters are 'less serious' repeaters than were those of a decade ago."

4. "Psychiatric techniques for rehabilitation never were tried; the deplorable working conditions made success impossible-there was not enough time, case loads were too big, and salaries were so low that only the poorest psychiatrists could be recruited."

5. "You can't expect any system in which the criminal is seen for only a few hours a week to significantly change personalities which have been in the making for the

${ }^{10}$ Cf. Cressey, supra note 8 , at $24 \mathrm{r}$. 
whole period of the individual's life and which are characterized by deeply-hidden, unconscious problems; we can only keep chipping away."

6. "For administrative reasons, the program was changed in mid-stream; good progress was being made at first, but the program was sabotaged by the new administrator (governor, legislature)."

7. "The technique was effective enough, but the kind of criminals placed on parole changed; ten years ago the proportion of criminals amenable to change was much greater than at present."

8. "Had the technique not been introduced, the recidivism rates would be much higher than at present; the fact that there is no difference really indicates that the technique has been very effective."

9. "There are too many complex variables which were not controlled in the study; a depression (prosperity) came along and affected the recidivism rate; the newspapers gave so much publicity to a few cases of recidivism that parole was revoked even in many cases where genuine progress toward rehabilitation was being made."

Io. "The study is invalid because it used no control group, but it has pointed up the need for really scientific research on psychiatric techniques; we must continue the program and set up a ten-year experimental study which will reassess our potential, locate some of the transactional variables in the patient-therapist relationship, determine whether some therapists have what we may term 'treatment-potent personalities' and others have what we are tentatively calling 'recidivistic creativity,' identify whether the catalystically-oriented therapeutic climate is self-defeating when occupied by reagent-reacting patients, and measure the adverse effects of post-therapeutic family-warmth variables on favorably-prognosticated and emotionally-mature dischargees."

Each of these ten themes has an equivalent which is used if the research findings are in the reverse direction. Suppose the mythical research study indicates that after the ten-year program, the recidivism rates are significantly lower than the rates in the earlier period. Persons using the above vocabularies are then likely to accept the validity of the study. But this does not mean that popular vocabularies for justifying existing programs in the face of adverse research findings will not be brought into play. On the contrary, supporters of some other technique, perhaps one in use before the ten-year program was started, can now use the same vocabularies:

I. "In the ten-year period, the proportion of men amenable to change was much greater than in the prior period; the parole board cracked down and placed only good risks on parole, so the change would have occurred even if the technique had not been used." (See number 7 above.)

2. "Although the technique was the one officially used, I happen to know that many of the workers informally used methods which are consistent with my theory rather than with the theory officially designated as the one to be implemented." (See numbers 4,5 , and 6 above.) 
3. "There are too many complex variables which were not controlled in the study: the criteria for revoking paroles was changed, a depression (prosperity) was in effect ten years ago, and many parole violations were overlooked merely to prove the effectiveness of the program." (See number 9 above.)

4. "If the technique, rather than something quite incidental to it, were effective in changing criminals, an even larger proportion of the criminal group would have been rehabilitated; a medical cure is specific to a disease and cures it." (See numbers $\mathrm{r}, 2,3$, and 8 above.)

There is no need to elaborate this list. Additional slogans to match each of those given to justify research which shows no significant differences could be enumerated.

The themes we have listed, or variations on them, are heard wherever correctional work is being evaluated. Probation and parole workers argue that probation and parole have never been tried. Prison workers argue that probation has drained off the "good convicts." Psychotherapists in any system argue that the punitive and custodial aspects of the program make it impossible to do effective work or, alternatively, that one (two, six, twenty-seven) therapists should not be expected to have much effect on a criminal population of 2,000 ( $1,000,500,100)$.

Significantly, variations on these themes could be used, and probably were used, in reference to correctional systems in which the primary instruments expected to induce change in criminals were techniques for inflicting pain.

To a large degree, these arguments are the consequence of labeling as "correctional" almost anything convicted criminals are expected to do. This is most easily discernible in prisons where whatever is done with prisoners to keep them occupied and/or productive and quiet is likely to be called a correctional measure. In the I920's and early I930's, prisoners were expected to work in prison factories, and these work programs were said to be rehabilitative. In the depression years, when the prison factories declined and prison populations increased, inmates were enrolled in prison schools. Enrollment in academic or vocational education classes became a correctional technique. Shortly after smoking privileges, canteen privileges, radios, and television are introduced-perhaps for humanitanian or custodial reasons -they are viewed as part of the correctional program. When psychiatrists, social workers, psychologists, and sociologists were employed to occupy some of the inmates' time and, further, to drain off some of the "rumbles" caused by disturbed inmates, thus contributing to a quiet, smooth-running prison, their services came to be labeled as correctional or rehabilitative. Even the salary of a man who supervises an institution's food and sanitary services is likely to be charged to the "care and treatment" (corrections) budget.

The same kind of observation can be made of general noninstitutional programs and of specific techniques within these programs. When prisons are overcrowded and inmates are, therefore, assigned to prison farms, camps, road-building crews, or parole, we argue that such assignment is a correctional technique. Alternatively, we 
keep inmates out of prisons by suspending sentences and requiring recipients of this action to file a monthly report with a probation officer, naming this a rehabilitative device. Not too long ago, a parole agency might equip its officers with guns and order them to "correct" parolees by watching them carefully. In more modern agencies, we hire only men with college degrees and ask them to do something (unspecified) different from that done by gun-carrying parole officers; this something, also, is corrective.

\section{VI}

\section{Some Theories of Personaltty, Crime, and Correction}

If correctional work were scientific, each correctional technique would be established on a rational basis. We would be reasonably sure that men commit crime in certain describable circumstances and not in others, and then we would set out to modify these crime-producing circumstances. Utilization of each correctional technique would be an experiment designed to test the validity of a theory of crime causation. Stated in another way, from a theory of crime causation, we would predict that certain techniques would work and others would not. If the technique were carefully administered under experimentally-controlled conditions but yet did not change criminals, we would be able to conclude either that (a) the theory on which the technique was based is wrong, or (b) the technique used was not consistent with the theory. Because correctional work is carried out under the kind of conditions we have already described-conditions which can scarcely be characterized as scientific-we are unable to draw either conclusion. The techniques in use certainly are not derived from precise statements of criminological theory.

Yet, there is a possibility that some order can be imposed on our rather disorderly conduct. Perhaps in the long run, we will find that some technique introduced for nontheoretical reasons "works." If this occurs, then we can, by working backward, develop a plausible theory of crime causation. "If practical programs wait until theoretical knowledge is complete, they will wait for eternity, for theoretical knowledge is increased most significantly in the efforts at social control."11 Although the various techniques currently in use were not necessarily introduced for theoretical reasons, we can discern, at least, that some of them are fairly consistent with standard theories of personality, crime causation, and rehabilitation.

At present, there are two general and popular, but contradictory, principles for the correction of criminality. These two principles-the "group-relations principle" and the "clinical principle"-are, in effect, theories of rehabilitation. Some correctional techniques are somewhat consistent with one or the other of them, some with both, and some with neither. The two principles are the logical outgrowths of two alternative theories of crime causation. These theories of crime causation, in turn, are applications to a specific kind of behavior, criminality, of two even more general theories of the relationship between personality on the one hand, and social relation-

\footnotetext{
${ }^{11}$ Sutherland \& CRESSEx, op. cit. supra note 2 , at 3 .
} 
ships on the other. We shall briefly identify the two theories of personality and the two criminological theories and then shall proceed to the two principles of reformation.

As Stanton and Schwartz have pointed out, behavioral scientists at one pole think of the "organization" of social interaction and "personality" as two facets of the sarne thing. ${ }^{12}$ The person is viewed as a product of the kinds of social relationships and values in which he participates; he obtains his satisfactions and, in fact, his essence, from participation in the rituals, rules, schedules, customs, and regulations of various kinds which surround him. Moreover, the person (personality) is not separable from the social relationships in which he lives. He behaves according to the rules (which are sometimes contradictory) of the large organization, called "society," in which he participates; he cannot behave any other way.

On the other hand, behavioral scientists at the opposite pole think of the individual as essentially autonomous, and they consider his interaction with rules and regulations of society and other organizations as submission rather than participation. "Personality" is an outgrowth of the effect that the "restrictions" necessary to organization have on an individual's expression of his own, pristine, needs. These behavioral scientists emphasize "individual self-determination" and make a distinction between the "real" or "natural" part of the person and the "spurious," "artificial," or "consensual" part. The former is viewed as primary, free, and spontaneous; the latter (obtained from the social relationships making up society) is formal, secondary, and restrictive.

Certainly the two theories of the relationship between personality and culture are more complex than this simple statement implies, and probably few behavioral scientists maintain one or the other of them explicitly and with no qualifications. But these two ideas, in form even more garbled and unqualified than we have used, have made their way into correctional work and have become the basis, indirectly, at least, of correctional techniques.

Consistent with the first general theory is criminological theory which maintains, in essence, that criminality is behavior which the person in question has appropriated from the social relationships in which he has been participating. Crime, like other behaviors, attitudes, beliefs, and values which a person exhibits, is the property of groups, not of individuals. ${ }^{13}$ Criminality is not just the product of an individual's contacts with certain kinds of groups; it is, in a very real sense, behavior which is "owned" by groups rather than by individuals. A man who participated exclusively in organizations of social relationships (groups, societies) which had a monopoly on criminality would exhibit criminal behavior, just as a person who participated exclusively in groups owning only law-abiding behaviors would be law-abiding. But since most organizations own both criminal behavior and law-abiding behavior

${ }^{12}$ Alfred H. Stanton \& Morris S. Schwartz, The Mental Hospital 37-38 (1954). See also Cressey, Rehabilitation Theory and Reality, II, Cal. Youth Authority Q., no. 2, 1957, p. 40.

${ }^{13}$ Cartwright, Achieving Change in People: Some Applications of Group Dynamics Theory, 4 Human ReLATIONS 381 (I95I). 
("honesty is the best policy, but business is business"), the behavior exhibited by any member of the organization will depend upon his differential participation in one or the other of the behaviors owned by the organization. The "differential association" theory is a good example of criminological theories of this kind. ${ }^{14}$

Consistent with the second general theory of personality is criminological theory maintaining, essentially, that criminality is a personal trait or characteristic of the individual exhibiting the behavior. An extreme position is that criminality is a biological phenomenon. Much more popular is the theoretical position that criminality is a psychological defect or disorder, or a "symptom" of either. The criminal is one who is unable to canalize or sublimate his "primitive," individualistic, antisocial impulses or tendencies, ${ }^{15}$ who may be expressing symbolically in crime some unconscious wish or urge arising from early traumatic experiences with the "restrictions of society,"16 or who suffers from some other individual psychological trait or condition. In any case, criminality is the property of the individual exhibiting it. Perhaps the criminal is "unable to accept the restrictions of society" ${ }^{17}$ perhaps his experiences in social relationships have given him unconscious urges which, when expressed, are criminalistic and beyond his control; perhaps they have built up in him a deep resentment of authority, latent hostility, or free-floating aggression. The essential notion here is that a "healthy" personality is one which does not own criminality because it has been permitted freely to express itself in numerous alternative ways.

The group-relations principle of reformation is based on the first polar type of theory about the relationship between personality and culture and the first kind of criminological theory. The basic notion is that attempts to change the criminal behavior of a person must be directed at modification of the groups owning the behavior. If the behavior of a man is an intrinsic part of the groups to which he belongs, then attempts to change that behavior will succeed only if the groups are somehow modified. While this principle is generally accepted in modified form by sociologists and social psychologists, there has been no consistent or organized effort to base techniques of correction on it. Many correctional practices and programs arising in the past one hundred years, however, have been indirectly, at least, consistent with it. Only in this way has the theory that changing the social relationships of offenders will modify criminality been implemented.

Among the more general programs which are, implicitly, consistent with the group-relations principle are probation and parole, where the offender is to be integrated into sets of social relationships in which criminality as a way of life is truly taboo. Similarly, even imprisonment as we now know it may be viewed as an un-

\footnotetext{
Is SutHerLand \& CREssey, op. cit. supta note 2, at 74-81.

${ }^{15}$ Sheldon \& Eleanor T. Glueck, Delinquents in the Making I62-63 (1952); Ruthi Jacons Levy, Reductions in Recidivism Throvgh Therapy 16, 28 (194I).

${ }^{10}$ Lukas, Crime Prevention: A Confusion in Goal, in Paul W. Tappan (Ed.), Contemporary ConRECTION 397 (195I).

${ }^{17}$ McCorkle, Group Therapy in the Treatment of Offenders, Fed. Prob., Dec. 1952, p. 22.
} 
successful system for attempting to force criminals to become members of organizations which do not own criminality, but, instead, own anticriminal behavior.

Within probation and parole systems, a precise, scientific, technique which is consistent with the group-relations principle has yet to be invented. Rather than descriptions of techniques, we find statements that the individual is to be rehabilitated by "gaining his confidence and friendship," "stimulating his self-respect," "manipulating his environment," "providing a supportive atmosphere," or "changing his group relations." It is necessary to know how confidence is secured, how self-respect is stimulated, how the environment is to be changed, what a supportive atmosphere is and how it is to be created, and how group relations can be changed. ${ }^{18}$

The same difficulty arises in connection with techniques used within prisons. Academic and vocational education are consistent with the group-relations principle to the extent that they are directed toward changing the offender's postinstitutional group relationships. Conceivably, this is successful in some cases. A popular but apparently fallacious assumption is that passing through an educational course, such as eighth-grade arithmetic, should make bad citizens (prisoners) good, because passing through such courses is a characteristic of good citizens. But it may be hypothesized that such courses are "correctional" only to the degree that they change inmates' postrelease associations. Similarly, vocational education courses are often assumed to correct inmates by imparting vocational skills to them, thus enabling ex-convicts to earn a living "so they do not have to return to crime." But the implication of the group-relations principle is that training men to be, say, bricklayers will not automatically correct their criminality. Conceivably, however, the newlyacquired skill might in a few cases have the effect of directing inmates into essentially anticriminal social relations upon discharge.

Prison labor is subject to the same kind of analysis. Ordinarily the assumption is that nonpunitive labor of almost any kind will instill in inmates "habits of industry" so that in the postrelease period, they will work in acceptable occupations and will not commit crimes. This assumption is similar to earlier assumptions that punitive labor, or punishment of almost any kind, will "tame" the criminal and make him law-abiding. Alternatively, we can assume that work in prisons is corrective largely to the extent that it is conducive to changes in social relations upon discharge, but it also contributes to the morale of inmates so that they are psychologically better equipped for making such changes. ${ }^{19}$ It is at least plausible that in some cases, possession of work and social skills learned in prison affects the exconvict's social mobility and that as he moves from the status of an unskilled worker,

\footnotetext{
${ }^{18}$ In the writer's statement on how to change criminals in a manner consistent with the differentialassociation theory, it was necessary to assume that "small groups existing for the specific purpose of reforming criminals can be set up by correctional workers and that criminals can be induced to join them." Cressey, Changing Criminals: The Application of the Theory of Differential Association, 56 AM. J. Sociology II6 (1955).

${ }^{10}$ SUTHERLAND \& CRESSEY, op. cit. supra note 2, at 522.
} 
an uneducated person, or an unemployed person to another status, his social relationships change in such a manner that his attitudes toward legal norms change.

Individual and group psychotherapy are rapidly becoming popular correctional techniques, both in prisons and in probation and parole. In individual psychotherapy, the psychological needs of individual inmates are of primary consideration, and the assumption is that correction of any psychological disorder or problem the inmate may have will change his criminality. Alternatively, adherents of the grouprelations principle assume that individual psychotherapy is effective in changing criminality to the extent that it serves as a stimulant or inducement to changes in social relationships. The criminal's psychological problems may be relieved, but this has little or no effect on his reformation unless his relationships with the groups owning the criminality he has been exhibiting are modified. Conceivably, interaction with a psychotherapist is just as effective in stimulating such changes as is interaction with a teacher, tradesman, or work-crew foreman.

Group therapy as a correctional technique is not necessarily consistent with the group-relations principle. Rather, a popular assumption is that group therapy, like individual therapy, corrects criminality by correcting individual psychological disorders. ${ }^{20}$ The emphasis in the "group work" of correctional agencies, such as probation offices, usually is on the role of the group in satisfying the psychological needs of an individual ${ }^{21}$ or in some way enabling the individual criminal to rid himself of undesirable psychological problems. There is almost unanimous opinion. that group therapy is an effective technique for treating mental patients, principally because isolated and egocentric patients are assimilated into the clinical group. ${ }^{22}$ But the group-relations principle implies that for correcting criminals there must be more than this; and in treatment based on this principle, the aim is not mere reduction of isolation and belligerence of prisoners as they operate in the prison situation (although this is important to the smooth operation of the institution), but the provision of positive opportunities for integration into groups which own an abundance of anticriminal values and behaviors. Again, interaction in a clinical group might be considered effective as a correctional technique to the extent that it gives the participants experiences in the role of a law-abiding person and to the extent that these experiences carry over to affect the kind of social involvement the participants experience when they become ex-convicts.

The clinical principle of reformation is consistent with the second type of theory about personality and the second kind of criminological theory. If criminality is an individual disorder, then, like a biological disorder, it should be corrected on a clinical basis. Consistent with the most extreme position is the notion that the

${ }^{20}$ Cressey, Contradictory Theories in Correctional Group Therapy Programs, Fed. Prob., June 1954, p. 20.

${ }^{21}$ See the discussion by Robert G. Hinckley \& Lydia Hermand, Group Treatment in PsychoTHERAPY 8-II (I95I).

${ }^{23}$ See Clinard, The Group Approach to Social Reintegration, 44 AM. Socrological Rev. 257 (1949); S. R. Siavson, An Introduction to Group Therapy I (1943); William C. Menninger, Psycuitatry IN A Troubled World 316 (1948). 
criminal's anatomy or physiology is to be modified through lobotomy, castration, modification of glandular functioning, or something else. Much more popular is the theory that the individual disorders producing criminality are psychological in nature and are, therefore, to be corrected through psychological attention. But in either case, the implication is that criminality should be corrected or treated clinically. In a sense, criminality is viewed as analogous to an infectious disease like syphilis-while group relationships of various kinds are necessary to the disorder, the disorder can be eradicated in a clinic, without reference to the conditions under which it was acquired. "Individualized treatment" usually refers to an attempt to correct some characteristic of the individual which is believed to underlie his criminality.

Individual psychotherapy, as a system for correcting criminals, is perhaps the best example of a current correctional technique based upon the clinical principle. Similarly, social casework has been greatly influenced by psychiatry, and as a result, many of the "diagnoses," "prescriptions," and "therapies" recommended or administered by social caseworkers attached to courts, prisons, and other agencies dealing with criminals are in clinical terms.

Because criminality is an expression of psychological disorders, it is to be corrected by elimination of the disorders. But because the disorders, in turn, spring from the restrictions society has placed on "free" individuals, correction of them must be in the form of modifying the impact of the restrictions on the individual. Although this might have reformation of society as one of its implications, individual criminals are to be corrected by giving them relief from the restrictions-in the form of "ventilation," "catharsis," "acting out" and other devices for removing "tensions," "aggression," "unconscious tendencies and wishes," and other individual disorders. If criminality is an expression of an individual disorder, then attempts to change criminal behavior will succeed only if this disorder is remedied. Many of the correctional techniques and programs arising in recent times have been indirectly consistent with this principle, as well as with the group-relations principle.

Probation and parole, as general programs, permit criminals more freedom than is possible if they are incarcerated, and, therefore, these systems reduce the intensity of the war between the individual and his society. Since criminality is an outgrowth of "undue" restriction of the individual by society, it is not logical to restrict the criminal further in attempts to correct him. Probation and parole are, then, corrective, even if they are only less restrictive than imprisonment. Similarly, in recent years, adherents of the clinical principle have emphasized the importance of making the prison itself less restrictive than formerly, presumably on the assumption that a "relaxed discipline" or "therapeutic climate" will enable inmates better to "act out" and in other ways adjust to the restrictions of society.

As is the case with the group-relations principle, scientific techniques for implementing the clinical principle within probation and parole systems have not been invented. We learn that offenders are to "gain insight," "relieve emotional tensions," 
"sublimate," etc.; but we do not know precisely how this is to be done. Similarly, we must know how, or whether, these processes produce anticriminality or, at least, noncriminality. Even if we had a precise statement of how to rid criminals of emotional tensions, for example, this action might have little to do with changing the criminality of behavior.

Most "correctional techniques" used in prisons are consistent with the clinical principle only in very indirect ways. It may be hypothesized that academic and vocational education are effective only to the extent that they permit the individual to express himself, sublimate antisocial tendencies, or escape from the restrictions on an uneducated person. It is not sufficient merely to implant knowledge or vocational skills; the education in a few cases might be effective because it alleviates, partially at least, the criminals' personal psychological problems. Similarly, labor in prisons is corrective largely to the extent that it enables individual inmates to escape from the rather harsh, restrictive, unstimulating environment which characterizes many institutions.

Individual and group therapy are, of course, consistent with the clinical principle and have been introduced into correctional work by adherents of the second type of personality theory. Group therapy, for example, both enables and forces the participants to "get beneath the surface," "adjust to reality," identify their individual traits in terms such as "resentment of authority," "feelings of guilt," "frustration," and "oedipus complex," and to dissipate the "tensions" and "anxieties" arising from such traits. ${ }^{23}$ In the words of one writer, "the future of group therapy in correctional work is bright because it offers help to a greater number of individuals and permits the release of pent-up hostility and aggression which, among more aggressive groups, frequently breaks out in open conflict." ${ }^{24}$

\section{VII}

\section{Conclusions}

The foregoing discussion has led to the rather obvious conclusion that most of the "techniques" used in "correcting" criminals have not been shown to be either effective or ineffective and are only vaguely related to any reputable theory of behavior or of criminality. To a degree, this is a consequence of the kinds of theories we have, as well as of the vested interests practical men and others have in the administration of specific kinds of programs. Many of the techniques consistent with the group-relations principle and the theory on which it is based could not be implemented in a society where correctional workers, like other men, work only an eight-hour day and forty-hour week. And many of the "diagnoses" which are consistent with the clinical principle and its theory call for techniques and/or programs which no correctional agency could possibly afford. What is needed is a correctional

\footnotetext{
${ }^{23}$ See McCorkle, supra note ${ }_{77}$; Slavson, Group Psychotherapy in Delinquency Prevention, 24 J. Ed. Sociozogy 45 (1950); Fuller, Group Therapy for Parolees, 14 Prison Wordd 9-1 1 (1952).

${ }^{26}$ Kesselman, Book Review, 2 INT't J. Group Psrchotherapy I94 (1952).
} 
technique which is explicitly based on a theory of behavior and of criminality and which can be routinely administered by a rather unskilled worker in the framework of the eight-hour shift. Caution is needed, however. Insulin and electric shock treatment is more popular in state mental hospitals than is individual psychotherapy, but this greater popularity is not necessarily attributable to the fact that shock therapy is more effective or more consistent with behavioral theory. Rather, it probably is popular because it can be both routinely and cheaply administered. 